\title{
B type natriuretic peptide levels had high sensitivity but moderate specificity for detecting CHF in the emergency department
}

Maisel AS, Krishnaswamy P, Nowak RM, et al,for the Breathing Not Properly Multinational Study Investigators. Rapid measurement of B-type natriuretic peptide in the emergency diagnosis of heart failure. N Engl J Med 2002;347:161-7.

\section{QUESTION: In emergency department (ED) patients with dyspnea, what are the diagnostic properties of $B$ type natriuretic peptide (BNP) levels for detecting congestive heart failure $(\mathrm{CHF})$ ?}

\section{Design}

Blinded comparison of BNP levels with a confirmatory diagnosis of CHF made by 2 cardiologists who reviewed patient medical records.

\section{Setting}

5 sites in the US and 1 each in France and Norway.

\section{Patients}

1586 ED patients (mean age 64 y, 56\% men) who had shortness of breath as the most prominent symptom. Exclusion criteria included age $<18$ years, dyspnea clearly not secondary to CHF (eg, trauma or cardiac tamponade), acute myocardial infarction, renal failure, and unstable angina without dyspnea as the primary symptom.

Description of test and diagnostic standard The BNP level in blood or plasma samples from all patients was measured using the bedside Triage B type natriuretic fluorescence immunoassay (Biosite Diagnostics, La Jolla, CA, USA). 2 cardiologists (blinded to the BNP levels) independently reviewed all medical records pertaining to each patient and classified the diagnosis as dyspnea caused by CHF, acute dyspnea caused by noncardiac causes in a patient with a history of left ventricular dysfunction, or dyspnea not caused by CHF. Information reviewed by the cardiologists included a reading of the chest roentgenogram, medical history, results of tests of ventricular function, and the hospital course for admitted patients.

\section{Main outcome measures}

Sensitivity and specificity, and positive and negative likelihood ratios.

\section{Main results}

$47 \%$ of patients had CHF. Sensitivity and specificity and positive and negative likelihood levels for several cut points of BNP levels are shown in the table. The area under the receiver operating characteristic curve was 0.91 (95\% CI 0.90 to 0.93$)$.

Source of funding: Biosite.

For correspondence: Dr A S Maisel, Veterans Affairs Medical Center, San Diego, California, USA.

amaisel@ucsd.edu

Abstract and commentary also published in ACP Journal Club
Diagnostic characteristics of $B$ type natriuretic peptide levels for detecting congestive heart failure in patients with dyspnea*

\begin{tabular}{lllll}
$\begin{array}{c}\text { Cut points } \\
(\mathbf{p g} / \mathrm{ml})\end{array}$ & $\begin{array}{l}\text { Sensitivity } \\
(95 \% \mathrm{CI})\end{array}$ & $\begin{array}{l}\text { Specificity } \\
(\mathrm{Cl})\end{array}$ & +LR & -LR \\
\hline 150 & $85 \%(82$ to 88$)$ & $83 \%(80$ to 85$)$ & 5.00 & 0.18 \\
\hline 125 & $87 \%(85$ to 90$)$ & $79 \%(76$ to 82$)$ & 4.14 & 0.16 \\
\hline 100 & $90 \%(88$ to 92$)$ & $76 \%(73$ to 79$)$ & 3.75 & 0.13 \\
\hline 80 & $93 \%(91$ to 95$)$ & $74 \%(70$ to 77$)$ & 3.58 & 0.09 \\
\hline 50 & $97 \%(96$ to 98$)$ & $62 \%(59$ to 66$)$ & 2.55 & 0.05 \\
\hline
\end{tabular}

\section{Conclusion}

In emergency department patients with dyspnea, B type natriuretic peptide levels had high sensitivity but moderate specificity for detecting congestive heart failure.

\section{COMMENTARY}

A test that could help establish the diagnosis of CHF in patients with dyspnea would be a boon to the clinician; such a test is described in the study by Maisel $e t$ al. Already shown to be useful in predicting functional capacity ${ }^{1}$ and outcome ${ }^{2}$ in patients with CHF, the bedside BNP assay was field tested in the toughest of proving grounds, the ED. How did it fare?

Quite well, judged against the final diagnosis of 2 independent cardiologists in possession of all clinical data available from the patient's hospital encounter. Using a cut point of $100 \mathrm{pg} / \mathrm{ml}$, the assay had $90 \%$ sensitivity and $76 \%$ specificity and contributed useful information when added to clinical data.

Could the study have used a better gold standard? An absolute standard for the diagnosis of CHF does not exist. Even if a pulmonary artery catheter is in place, it can be difficult to decide if rales are from CHF or atelectasis. The assay was superior to the validated Framingham and National Health and Nutrition Examination Survey Scores for establishing the diagnosis of CHF.

Another report from the same group ${ }^{3}$ shows how the BNP assay compares with the ED physician's determination: It increased diagnostic accuracy by $7 \%$ and would have corrected the diagnostic impression a substantial number of times, even where the clinician was certain of the diagnosis. That same study also supplies a nomogram to calculate the probability of CHF given a BNP level and a pretest likelihood of CHF for those who prefer a quantitative approach to clinical decision making. One can only guess how much heparin, albuterol, or antibiotic would be saved if a reliable diagnosis of CHF could be made in the ED! Although it falls short of perfection, the BNP assay improves our ability to get this diagnosis right.

Ellis Lader, MD New York University School of Medicine Kingston, New York, USA

1 Kruger S, Graf J, Kunz D, et al. Brain natriuretic peptide levels predict functional capacity in patients with chronic heart failure. J Am Coll Cardiol 2002; 40:718-22.

2 failure. J Am Coll Cardiol 2002;40:718-22. a combination of cardiac troponin $\mathrm{T}$ and brain natriuretic peptide in patients hospitalized for worsening chronic heart peptide in patients hospitalized for worsening chronic heart
failure. Am J Cardiol 2002;89:691-5.

3 McCullough PA, Nowak RM, McCord J, et al. B-type natriuretic peptide and clinical judgment in emergency erly (BNP) multinational study. Circulation 2002;106:416-22. 